\title{
Escherichia coli recA deletion strains that are highly competent for transformation and for in vivo phage packaging
}

(Bacteriophage $\lambda$; cosmids; phasmids; phosmids; plasmid vectors; recombinant DNA)

\section{David M. Kurnit}

Howard Hughes Medical Institute, Departments of Pediatrics and Human Genetics, University of Michigan Medical Center, Ann Arbor, MI $48109-0650$ (U.S.A.)

Received by D.M. Skinner: 3 January 1989

Accepted: 20 March 1989

\section{SUMMARY}

I describe the construction of a variety of Escherichia coli recA deletion strains designed to facilitate molecular cloning. These recA deletion strains permit the efficient cloning of foreign inserts carried in plasmid, phage, cosmid, phasmid (phage-plasmid hybrid) or phosmid (phage-cosmid hybrid) vectors.

\section{INTRODUCTION}

Cloning of large, foreign, inserted DNA fragments is performed in recA-deficient strains of $E$. coll, to minimize rearrangements due to homologous recombination among repetitive elements often found in complex genomes. For this purpose, several rec $A^{-}$ cloning hosts have been developed. For transformation, the competent strains $\mathrm{HB} 101$ (recA 13) (Boyer and Roulland-Dussoix, 1969), DH1 (recA1)

\footnotetext{
Correspondence to: Dr. D.M. Kurnit, Howard Hughes Medical Institute, 1150 W. Medical Center Drive/MSRB 13520 , Ann Arbor, MI 48109-0650 (U.S.A.) Tel. (313)747-4747; Fax (313)936-9353.

Abbreviations: ATCC, American Type Culture Collection; $\Delta$, deletion; gp, gene product; IPTG, isopropyl- $\beta$-D-thiogalactopyranoside; ${ }^{\mathrm{R}}$, resistance; ${ }^{\mathrm{s}}$, sensitivity; Tc, tetracycline; $\mathrm{Tn}$, transposon; wt, wild type; XGal, 5-bromo-4-chloro-3-indolyl$\beta$-D-galactopyranoside; ::, novel joint.
}

(Hanahan, 1983) and its derivatives (including JM 109; Yanisch-Perron et al., 1985) and SCS-1 (Stratagene Cloning Systems), have been used. For in vivo packaging of cosmids carrying $\lambda \cos$ sites, BHB3175 (recA 1) (Poustka et al., 1984) was constructed; however, this host suffers from a disappointingly low efficiency of cosmid establishment and packaging.

Each of the above cloning strains carries a leaky point mutation of the rec $A$ gene. Clark and coworkers have developed a series of strains carrying $\mathrm{Tn} 10$-mediated deletions of the $r e c A$ structural gene, that occurred following $\operatorname{Tn} 10$ insertion into the adjacent $s r l$ locus. In particular, $A(s r l-r e c A)$ 306: : Tn 10 (Willis et al., 1981) is particularly useful, as it deletes the entire rec $A$ structural gene. I transferred this deletion to a variety of $E$. coli $\mathrm{C}$ and $\mathrm{K}-12$ strains to create a series of $\operatorname{rec} A$ deletion strains specialized for cloning a variety of phage, cosmid, phasmid and phosmid cloning vectors. 
TABLE 1

Bacterial strains

\begin{tabular}{|c|c|c|}
\hline Strains ${ }^{a}$ & Genotype & Reference $^{c}$ \\
\hline C-1a & Prototrophic $\mathrm{C}-1^{\mathrm{b}}$ & 1 \\
\hline $\mathrm{C}-\mathbf{3 1 5 0}$ & C-1 a $\Delta($ srl-recA $) 306$ & 1 \\
\hline C-3152 & $\mathrm{C}-3150(\mathrm{P} 2 \lg c c)$ & 2 \\
\hline C-3154 & $\mathrm{C}-3150(\mathrm{P} 2$ Oam7) & 3 \\
\hline C-3155 & $\Delta($ srl-recA $) 306$, thr-5, leu-5, xan-1, strl (P2 A am 129) & 4 \\
\hline DK1 & 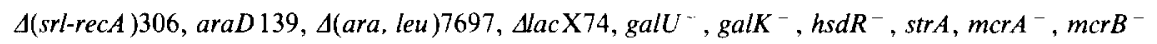 & 5 \\
\hline DK8 & 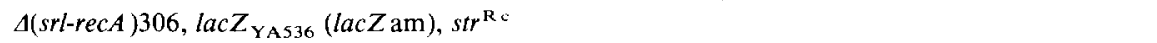 & 6 \\
\hline DK9 & $\Delta(\operatorname{srl}-r e c A) 306$, galK U42(am), galE ${ }^{*} \operatorname{trp}^{-}(\mathrm{am}), a_{r a}^{-}(\mathrm{am}), \operatorname{lac} Y_{\mathrm{T}} 6^{\mathrm{Rd}}$ & 7 \\
\hline DK37 & DK9 $(\phi 80 w t)$ & \\
\hline DK22 & DK1 $(\lambda 3169)$ & 5,8 \\
\hline MCL31 & HfrPO201 $\Delta(\mathrm{gpt}$-lac $) 5$ relA 1 rpsE2123 thi-1 supE44 TP3 $\Delta($ srl-recA $) 306:: \operatorname{Tn} 10$ & 9 \\
\hline
\end{tabular}

All bacterial strains are $\mathrm{F}^{-}$.

a DK1 (ATCC strain No. 35691): This $\triangle r e c A$ derivative of MC1061 (Casadaban and Cohen, 1980) has the following useful properties: (1) High-transformation competence (about $10^{8}$ transformants/ $\mu \mathrm{g}$ supercoiled $\mathrm{pBR} 322$, using a simple $\mathrm{CaCl}_{2}$ transformation protocol); (2) a genotype lacking $E$. coli restriction barriers to molecular cloning: DK1 is $h s d R^{-} h s d M^{+} m_{c r} A^{-} m_{c r} B^{-}$(Casadaban and Cohen, 1980; Raleigh et al., 1988); (3) a good $\mathbf{K}-12$ host for $\mathbf{P} 4$ and $\mathbf{P} 2$, which is usually propagated on $E$. coli $\mathrm{C}$ strains that are $h s d R^{+}$and whose $m c r A$ and $m c r B$ genotype is unknown.

DK8: This $4 r e c A$ derivative of LG75 (Guarente et al., 1980) is lac $Z$ am, affording colorimetric detection of phages, cosmids, phasmids and phosmids carrying supF, that yield blue plaques or colonies in the presence of IPTG $+\mathrm{XGal}$.

DK9: This $\Delta r e c A$ derivative of $\mathrm{N} 953$ is a galE ${ }^{-}$strain that carries amber mutations in $\operatorname{trp}$ and galK, yielding both positive and negative selection for carriage of supF by either cosmids, phasmids or phosmids (Russell et al., 1970).

DK37 is a $\phi 80$ wt lysogen of DK9 that permits selection for or against carriage of supF by the $\lambda$ phasmid vector Sumol5A (Kurachi et al., 1989), whose $\lambda$ lytic functions are repressed by the $\phi 80 \mathrm{cI} \mathrm{gp}$.

DK22: $\lambda 3169$ ( $b$ 2red3imm $434 c$ Its $S$ am7) (Poustka et al., 1984) lysogen of DK1 is a useful in vivo packaging host for cosmids that utilize $\lambda$ cohesive ends. This strain was constructed as an alternative to BHB3175 (Poustka et al., 1984), a $\lambda 3169$ lysogen of the recA 1 strain, DH1. Following in vitro packaging and transfection, cosmid libraries may be established by selecting for appropriate antibiotic resistant colonies at $32^{\circ} \mathrm{C}$, a permissive temperature for the thermolabile repressor. For a variety of cosmids with $\lambda \cos$ sites and either ColE1or $\lambda$-based replicons, the relative colony-forming efficiencies, following in vitro packaging and transfection, were 1 for DH 1 and DK 1 , 0.3 for DK22, and $10^{-3}$ for BHB3175. This improved efficiency makes it practical to establish cosmid libraries directly in DK22, with the advantage that the libraries subsequently may be packaged directly in vivo without further amplification simply by shifting to $42^{\circ} \mathrm{C}$, the nonpermissive temperature for the thermolabile repressor. The cause of inefficient cosmid establishment in BHB3175 is not known; perhaps cleavage of repressor by residual recA activity (Roberts et al., 1978) in the recAl (Low, 1968) strain BHB3175 is responsible for this difference.

b Adapted to grow on minimal medium.

c Our strain is $s t r^{R}$ although this is not in the published genotype of LG75.

d DK9 is a recA derivative of N953; N953 is an $\mathrm{F}^{-} S u^{\circ}$ derivative of MBO (gift of M. Gellert).

- References: 1, Sasaki and Bertani (1965); 2, Sironi (1969); 3, Lengyel et al. (1973); 4, Lindahl (1970; 1971); 5, Casadaban and Cohen (1980); 6, Guarente et al. (1980); 7, Russell et al. (1970); 8, Poustka et al. (1984); 9, Lorence and Rupert (1983).

\section{EXPERIMENTAL AND DISCUSSION}

Table I lists the $\operatorname{Arec} A$ deletion strains constructed. The deletion was transferred either by interrupted mating or P1 transduction. Interrupted matings were performed using the Hfr strain MCL31 (Lorence and Rupert, 1983), with interruption accomplished by vortexing for $30 \mathrm{~s}$ at top speed on a VWR Genie-mixer. Interruption was performed at
5 -min intervals; transfer of $\mathrm{Tc}^{\mathrm{R}}$ marker was first seen 10 min after mating was initiated, and strains used were derived from this 10 -min time point. For P1 transductions, a Plvir lysate on MCL31 was used to cotransduce $\mathrm{Tc}^{\mathrm{R}}$ and $\Delta \mathrm{rec} A$. In each strain:

(1) The original genetic properties were confirmed following transfer of the $\operatorname{rec} A$ deletion.

(2) The $r e c A^{-}$phenotype was confirmed by demonstrating both increased sensitivity to ultraviolet 
irradiation and by demonstrating an inability to plate $\mathrm{red}^{-} \mathrm{gam}^{-} \lambda$ phages that plate on the otherwise isogenic rec $A^{+}$parent strain (Clark, 1973).

(3) Following establishment of the $A(\operatorname{srl}-\mathrm{rec} A)$ $306:$ : $\mathrm{Tn} 10$ phenotype (i.e., $r e c A^{-} \mathrm{Tc}^{\mathrm{R}}$ ), fusaric acid counterselection (Bochner et al., 1980) was performed using the modifications of Maloy and Nunn (1981) to select $\mathrm{Tc}^{\mathrm{S}}$ cells that had deleted $\mathrm{Tn} I 0$. Such $\mathrm{Tc}^{\mathrm{S}}$ strains were able to express $\mathrm{Tc}$ resistance following transformation with plasmids that confer resistance to this antibiotic.

In addition to the $E$. coli $\mathrm{K}-12$ strains listed in Table I, we describe elsewhere a number of $\triangle \mathrm{rec} A$ E. coli $\mathrm{C}$ strains adapted for $\mathrm{P} 4$ and $\mathrm{P} 2$ cloning (D.M.K., R.L. Neve, F.S. Lee, R. Lagos and R. Goldstein, manuscript submitted). These include hosts for plating P2 (C-3150) (Sasaki and Bertani, 1965), P4 (C-3152) (Sironi, 1969), and for selecting for (C-3154) (Lengyel et al., 1973) or against (C-3155) (Lindahl, 1970; 1971) carriage of supF by P4 phasmids.

These $\Delta r e c A$ strains of $E$. coli have been used to clone a wide variety of vectors based on $\mathrm{Col} / \mathrm{E} 1, \lambda$ and $\mathrm{P} 4$, carrying up to $40 \mathrm{~kb}$ inserts from a variety of complex genomes. For both $\lambda$ - and P4-based cloning systems, we have utilized the recombination-based assays of Seed (1983) and Poustka et al. (1984) to generate phages, cosmids, phasmids and phosmids that carry stably such large inserts with direct repeats in these rec $A$ deletion strains. All strains are available either from the author or from ATCC, as indicated.

\section{ACKNOWLEDGEMENTS}

Supported by NIH HD20118 and March of Dimes 6-501. D.M.K. is an Investigator, Howard Hughes Medical Institute. I thank Richard Goldstein, Laszlo Csonka and Brian Seed for helpful discussions.

\section{REFERENCES}

Bochner, B.R., Huang, H.C., Schieven, G.L, and Ames, B.N.: Positive selection for loss of tetracycline resistance. J. Bacteriol. 143 (1980) 926-933.

Boyer, H.W. and Roulland-Dussoix, D.: A complementation analysis of the restriction and modification of DNA in Escherichia coli. J. Mol. Biol. 41 (1969) 459-472.

Casadaban, M.J. and Cohen, S.N.: Analysis of gene control signals by DNA fusion and cloning in Escherichia coli. J. Mol. Biol. 138 (1980) 179-208.

Clark, A.J.: Recombination deficient mutants of $E$. coll and other bacteria. Annu. Rev. Genet. 7 (1973) 67-86.

Guarente, L., Lauer, G., Roberts, T.M. and Ptashne, M.: Improved methods for maximizing expression of a cloned gene: $\Lambda$ bacterium that synthesizes rabbit $\beta$ globin. Cell 20 (1980) 543-554.

Hanahan, D.: Studies on transformation of Escherichia coli with plasmids. J. Mol. Biol. 166 (1983) 557-580.

Kurachi, S., Baldori, N. and Kurnit, D.M.: Sumol5A: a lambda plasmid that permits easy selection for and against cloned inserts. Gene (1989) in press.

Lengyel, J., Goldstein, R., Marsh, M., Sunshine, M. and Calendar, R.: Bacteriophage P2 morphogenesis: cleavage of the major capsid protein. Virology 53 (1973) 1-23.

Lindahl, G.; Bacteriophage P2: replication of the chromosome requires a protein which acts only on the genome that coded for it. Virology 42 (1970) 522-533.

Lindahl, G.: On the control of transcription in bacteriophage $P 2$. Virology 46 (1971) 620-633.

Lorence, M.C. and Rupert, C.S.: Convenient construction of recA deletion derivatives of Escherichia coli. J. Bacteriol. 146 (1983) 458-459.

Low, B.: Formation of merodiploids in matings with a class of $\mathrm{Rec}^{-}$recipient strains of Escherichia coli K12. Proc. Natl. Acad. Sci. ISSA 60 (1968) 160-167.

Maloy, S.R. and Nunn, W.D.: Selection for loss of tetracycline resistance by Escherichia coli. J. Bacteriol. 145 (1981) $1110-1112$.

Poustka, A., Rackwitz, H.-R., Frischauf, A., Hohn, B. and Lehrach. H.: Selective isolation of cosmid clones by homologous recombination in Escherichia coli. Proc. Natl. Acad. Sci. USA 81 (1984) 4129-4133.

Raleigh, E.A., Murray, N.E., Revel, H., Blumenthal, R.M., Westaway, D., Reith, A.D., Rigby P.W.J., Elhai, J. and Hanahan, D.: McrA and McrB restriction phenotypes of some $E$. coli strains and implications for gene cloning. Nucleic Acids Res. 16 (1988) 1563-1575.

Roberts, J.W., Roberts, C.W. and Craig, N.L.: Escherichia coli recA gene product inactivates phage $\lambda$ repressor. Proc. Natl. Acad. Sci. USA 75 (1978) 4714-4718.

Russell, R.L., Abelson, J.N., Landy, A., Gefter, M.L., Brenner, S. and Smith, J.D.: Duplicate genes for tyrosine transfer RNA in Escherichia coli. J. Mol. Biol. 47 (1970) 1-13.

Sasaki, L. and Bertani, G.: Growth abnormalities in Hfr E. coli strain C. J. Gen. Microbiol. 40 (1965) 365-376.

Seed, B.: Purification of genomic sequences from bacteriophage libraries by recombination and selection in vivo. Nucleic Acids Res. 11 (1983) 2427-2445.

Sironi, G.: Mutants of Escherichia coli unable to be lysogenized by the temperate bacteriophage P2. Virology 37 (1969) 163-176.

Willis, D.K., Uhlin, B.E., Amini, K.S. and Clark, A.J.: Physical mapping of the sri-recA region of Escherichia coli: analysis of transposon Tn 10 generated insertions and deletions. Mol. Gen. Genet. 183 (1981) 497-504.

Yanisch-Perron, C., Vieira, J. and Messing, J.: Improved M13 phage cloning vectors and host strains: nucleotide sequences of the M13mp18 and plC19 vectors. Gene 33 (1985) $103-119$. 